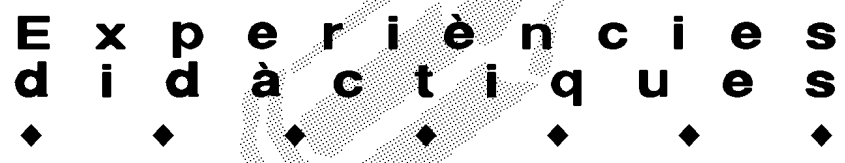

\section{JUGUEM COM JUGAVEN LES NENES I ELS NENS DE TÀRRACO}

\author{
Elena Venini Redín. Àrea de Didàctica i Organització Escolar. URV \\ M. Joana Virgili Gasol. Camp d'Aprenentatge Ciutat de Tarragona
}

\section{Introducció}

L'empremta romana a Tarragona s'explica amb claredat a través de les restes monumentals que es conserven. Però, i els seus habitants? Com era la seva vida? On són i què se n'ha fet, dels habitants de Tàrraco i dels seus descendents?

La necessitat de donar resposta a aquestes preguntes, de mostrar als infants d'una manera lúdica i propera al seu món que els romans som nosaltres, que som els hereus de la cultura, la llengua, els jocs, les tradicions, etc., ens va fer pensar que la millor forma d'apropar-nos-hi per reviure-ho era a partir de quelcom tan pròxim als infants com el joc. La paraula llatina ludus significa alhora diversió infantil, joc, esbarjo i escola, ja que no hi ha cap mot llatí que designi específicament el joc infantil o que tingui el significat genèric actual de joguina. I encara que el joc s'ha situat sempre en un context historicosocial, cal dir que han jugat els nens i les nenes de totes les èpoques i pobles. El joc és, per tant, una realitat quotidiana de l'infant que potencia l'interès per avançar en la comprensió més àmplia del passat. La metodologia emprada permetrà, a més, prendre-hi contacte directe i aportar recursos i materials perquè els alumnes accedeixin al seu coneixement des d'un punt de vista evolutiu, temporal i de coetaneïtat històrica.

L'objectiu és facilitar a l'alumnat l'aproximació a una de les realitats més atractives del nostre entorn social $\mathrm{i}$ cultural, i alhora proporcionar els recursos materials i metodològics imprescindibles per analitzar-lo i comprendre'l. Tanmateix, el joc és una activitat innata inseparable de la condició humana i respon a la necessitat pròpia de tots els infants de ser una font d'activitat, ja que als nens els cal moure's, tafanejar, veure coses, tocar-les i manipular-les. D'aquesta manera, els petits manifesten l'ànsia d'experimentar, crear, inventar, relacionar-se amb les persones, intercanviar les vivències, expressar les idees i sentiments, etc., és a dir, accions innates que juguen a favor nostre.

Es tracta d'un pla d'immersió en el qual més d'un miler d'alumnes de cinquè d'educació primària (el primer dia, dels centres públics i privats de la ciutat de Tarragona, i el segon, d'altres indrets), juntament amb els professors/es, participaran en els mateixos jocs que els nens i les nenes de Tàrraco.

Les jornades se celebren dins del projecte de ciutat de Tàrraco Viva des de fa deu anys. Es justifiquen perquè:

- Apropen l'alumne d'una manera lúdica al temps dels romans.

- Permeten adquirir el concepte de temporalitat, canvi, continuïtat i evolució de la història.

- És un projecte globalitzador entre tots els alumnes dels centres de Tarragona i comarques.

\section{Metodologia}

Fonamentem la metodologia activa basada en l'observació directa i personal, i potenciem el debat que impliqui el professorat i l'alumnat, que permeti la posada en comú i la redacció de conclusions finals. En definitiva, l'activitat ha estat dissenyada amb aquestes característiques didàctiques, perquè sigui:

- Variada, per aconseguir la motivació a través de diversos suports, processos, procediments, etc.

- Manipulativa, per assolir l'aprenentatge a través de l'acció.

- Experimental, perquè cada alumne/a visqui l'activitat com a part d'una experiència personal.

- Analítica, pel procés deductiu i l'extracció de conclusions que s'hi duen a terme.

- Interactiva, en què l'alumne/a treballa en grup i actua constantment.

- Visual i sensorial, amb una explicació basada en l'observació directa i indirecta, la comparació, etc.

En resum, els alumnes tocaran, manipularan, ordenaran objectes i imatges, deduiran, es posaran en el lloc dels altres, construiran, identificaran i experimentaran a través del joc. Ineludiblement veuran que la història no és només un llibre teòric que estudien a classe, sinó que el joc té una incidència fonamental en el present $i$ en el passat.

Com tots els treballs del Camp d'Aprenentatge (CdA, a partir d'ara), l'activitat comença i acaba a classe amb el professorat responsable del grup i s'integra dins del currículum escolar. Prèviament, el professorat del CdA imparteix l'activitat Roma a l'escola, que mostra als alumnes com era Tàrraco i com es desenvolupava la 


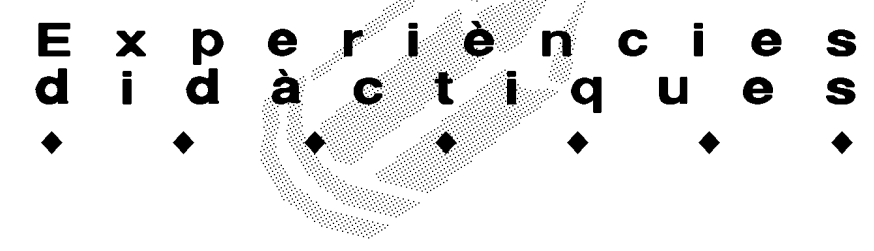

vida d'un nen/a des que naixia fins que era major d'edat. El contingut de la jornada es complementa amb un espectacle romà relacionat amb el tema, que varia cada any. Els treballs posteriors dels alumnes van dirigits a la recerca de nous jocs i de paral-lelismes entre els jocs romans i els actuals.

\section{El perquè de la jornada}

La idea de la jornada d'aprenentatge actiu "Juguem com jugaven les nenes i els nens de Tàrraco" va sorgir a partir de les qüestions que es formulaven els nens $i$ nenes després de visitar la necròpolis paleocristiana de Tarragona: "Què ha passat amb els romans? Tots morts, no?" Calia, per tant, donar una resposta entenedora que potenciés la capacitat deductiva dels alumnes a fi que arribessin, a través d'un element tan proper com el joc, a establir deduccions clares i a adonar-se de la nostra semblança amb els romans.

Els nostres objectius són:

- Aconseguir que els alumnes s'imbueixin dels conceptes de temporalitat i evolució històrica.

- Mostrar-los d'una manera lúdica i viva el món dels romans, acostar-los als jocs, descobrir els entreteniments de l'època i fer-los adonar que els jocs actuals no són tan llunyans dels antics.

- Aconseguir que sigui un projecte globalitzador que serveixi per a tots els alumnes dels centres de Tarragona i de la comarca.

- Apropar les joguines dels romans a l'alumne.

- Entendre el joc com un llenguatge universal i com a referent d'integració.

- Aconseguir la convivència participativa de tots els escolars.

El joc és un element motivador que interessa a les persones de totes les edats. Recordem, per exemple, el que ens diu Sèneca: "El que diferencia un home d'un nen és l'avidesa dels nens pels objectes com ossets, nous o petites peces de monedes, mentre que els homes volen or, plata o ciutats" (De constancia sapientis, XII,2).

Així doncs, el joc lligat als comportaments d'exploració i de curiositat constitueix el motor de l'aprenentatge i de la descoberta de l'infant. D'aquí en derivaria el seu aprofitament. Un cop establerta aquesta base de realització es va deduir que calia avançar més en el coneixement del joc, a través de fonts documentals romanes com textos, pintures, mosaics, relleus i murals de l'època. A tall d'exemple, citem alguns escriptors que en les seves obres expliquen alguns d'aquests jocs o bé en fan menció: Horaci a les Sàtires parla de construir cases petites, del joc de parells o senars i de com muntar a cavall dalt d'un bastó llarg; Ovidi a l'Heroides ens dóna a conèixer sis maneres de jugar amb nous: el castell de nous, els pendents, el triangle de nous, el joc de fer-les entrar en un forat al terra o dins d'una gerra i parells i senars; Virgili a l'Eneida ens parla de la baldufa; Hipòcrates, en la seva obra sobre el règim personal, recomana que per aconseguir mantenir-se en bona forma física cal jugar amb el cèrcol; Suetoni en El diví August ens descriu el joc de la morra. Són nombroses també les al-lusions als jocs de pilota i als tipus que existien, algun dels quals s'han adaptat amb bases per poder jugar.

\section{Història de la jornada}

La primera jornada es va celebrar el dia 1 d'abril de 1998 i hi van participar uns 540 nens i nenes d'alguns centres de Tarragona acompanyats dels seus professors. La bona acollida dels centres participants i l'èxit de la jornada va fer que el projecte s'integrés dins de Tàrraco Viva.

Des de l'any 2001, és a dir, des de la tercera jornada, els alumnes de primer curs de l'ensenyament de Mestre de la URV col-laboren en el monitoratge dels jocs romans com a darrera activitat pràctica que fan dins de l'assignatura de Didàctica General.

El nombre d'estudiants que hi han participat ha estat sempre molt elevat, la qual cosa ha permès atendre gran part dels espais de joc preparats. La participació ha estat la que es mostra a la taula 1.

La raó per la qual es va considerar important que hi intervinguessin els futurs mestres és ben senzilla. Representava una aportació didàctica imprescindible en la formació inicial de qualsevol ensenyant: un aprenentatge obtingut a partir d'una pràctica real, activa, allunyada d'òptiques transmissives sobre la manera d'ensenyar.

La participació ha esdevingut continuada, i a causa de les nombroses peticions l'any 2006 les jornades es van ampliar dos dies. La primera jornada acull tots els centres, ja que hi participen totes les escoles d'educació primària de la ciutat de Tarragona, i a la segona es reben els centres d'altres comarques de Tarragona que ho han sol-licitat, per estricte ordre de petició i fins a

\begin{tabular}{|cccc|}
\hline Any & Espais & Estudiants & Escolars \\
2001 & 70 & 125 & 876 \\
2002 & 80 & 120 & 916 \\
2003 & 89 & 136 & 1021 \\
2004 & 92 & 150 & 1200 \\
2005 & 110 & 218 & 1900 \\
2006 & 103 & 238 & 2500 \\
2007 & 142 & 310 & 2600 \\
\hline
\end{tabular}

Taula 1. Participació d'estudiants de l'ensenyament de Mestre de la URV i d'escolars d'educació primària a les Jornades de Tàrraco Viva. 




arribar al màxim d'alumnes que permet la nostra capacitat d'acollida. Per tant, uns 1300 acompanyats d'uns 300 professors gaudiran de 142 espais de joc que s'ofereixen al Camp de Mart de Tarragona. Hem d'esmentar que també hi col-laboren alumnes de l'IES Cal-lípolis, de l'IES Vidal i Barraquer i del Conservatori de Música.

Per gestionar el projecte ha estat imprescindible la coordinació de tres organismes: el Departament d'Educació, l'Ajuntament de Tarragona i la Universitat Rovira i Virgili, a través de la Facultat de Ciències de l'Educació i Psicologia.

\section{Repercussions didàctiques}

La conseqüència lògica d'aquesta immersió ha estat la plasmació d'un repertori ampli de jocs, normes, instruments i utensilis per jugar, i s'ha arribat a la reproducció posterior d'objectes $\mathrm{i}$ de taulers amb el complement necessari per poder jugar. Ha estat i és necessària una intensa tasca d'investigació a fi de cercar nous jocs amb les respectives normes. Aquesta investigació ha implicat que la consecució de reproduccions de jocs romans es plasmessin per escrit en el llibre Juguem com jugaven els nens i les nenes de Tàrraco, que s'ofereix als centres de Catalunya -o d'altres indrets-amb petició prèvia i en un bagul acompanyat del llibre dels jocs amb les indi- cacions didàctiques que el regeixen i les normes que s'hi proposen.

El desenvolupament de l'activitat s'inicia amb unes trobades de coordinació a l'aula habitual de classe de la URV, entre les quals hi ha els professors del CdA, la professora de didàctica i els alumnes de Magisteri dividits en grups i repartits per especialitats. Durant la trobada es presenta la jornada, la metodologia que s'ha d'aplicar i la relació dels jocs. Un cop en són coneixedors, escullen per parelles el joc més adient a les seves possibilitats, del qual es responsabilitzaran, tant pel que fa al bon ús, organització i, si cal, reposició del material, com a la recollida i retorn al punt d'origen, perquè es pugui utilitzar en òptimes condicions en la segona o posteriors jornades.

Se'ls donen indicacions didàctiques respecte a la metodologia i la importància de l'actuació del mestre, amb l'objectiu d'obtenir un bon rendiment dins de les possibilitats que ofereix el joc. També se'ls comuniquen les normes d'actuació durant la jornada: el temps que han de dedicar a cada grup d'alumnes per tenir cura dels horaris de les actuacions, les normes de comportament que han de demanar als nens, l'obligació de mantenir-se en el racó de joc i de respectar i no abandonar el material, i la necessitat d'emprar el català com a llengua vehicular tal com determina el Departament

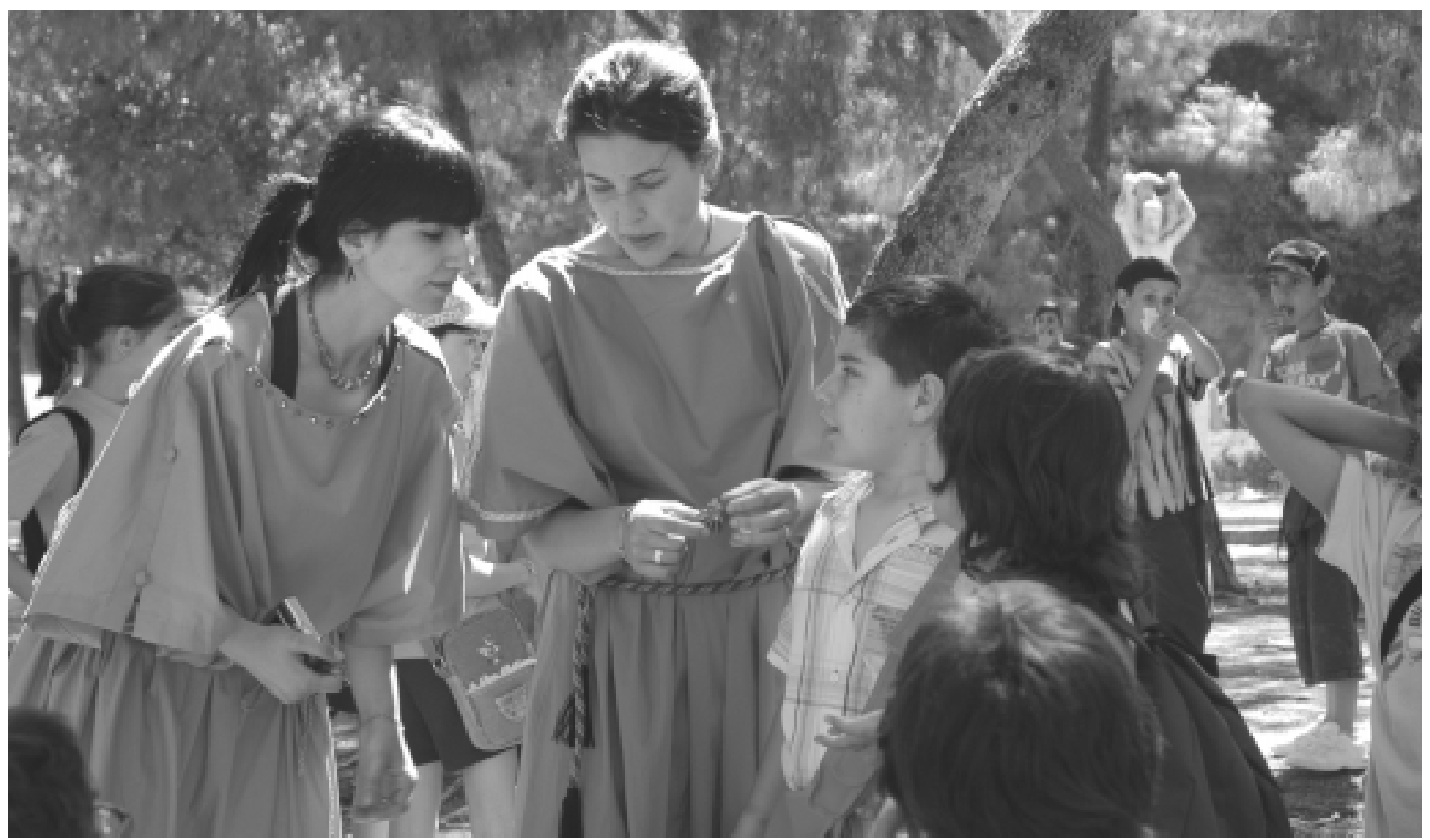






d'Educació i d'animar l'alumnat a participar-hi. També se'ls avisa de possibles irregularitats que hi poden haver, com ara l'assistència mèdica, que s'ha de dur a terme a través del servei mèdic corresponent, o la presència de la guàrdia urbana en el recinte en cas de necessitat. Se'ls lliura un dossier amb la informació detallada del joc que decideixen monitoritzar i un plànol del Camp de Mart perquè coneguin la seva situació. El dossier explica el nom del joc en llatí, l'equivalent en català, els materials que es proporcionaran i les instruccions sobre la manera de jugar.

S'ha de destacar la capacitat de resposta, dels alumnes-monitors, pel que fa a la participació activa, l'estructura organitzativa -promptitud i rapidesa en el muntatge i desmuntatge del seu espai de joc-, la implicació en el desenvolupament de l'activitat, la recepció il-lusionada del grup multitudinari d'alumnes amb ànsies desmesurades de joc i la valoració positiva de les jornades.

\section{Conclusions}

L'objectiu de la nostra proposta de treball és, per tant, que els alumnes adquireixin uns conceptes sobre un període històric, alhora que desenvolupin uns aprenentatges de tipus procedimental, que interioritzin uns valors, unes actituds i unes normes que finalment els permetin conjuntament ser protagonistes del propi aprenentatge.

Considerem que no han de concebre la història com un fet passat i no operatiu actualment, sinó que pretenem que siguin conscients que aquest passat ens ha configurat tal com som i que conèixer-lo ens ha permès entendre el present.

Demanem a l'alumne que sigui capaç de treballar en equip, de compartir i assumir responsabilitats. Aquesta proposta forma part d'un treball més ampli de coneixement de la ciutat i, en particular, d'aquesta època històrica. L'activitat comença i s'acaba a l'aula i la seva realització està totalment lligada al professorat i al centre que la realitza. Es tracta d'un treball multidisciplinari, ja que per a la realització correcta es necessita la intervenció de diferents àrees de coneixement: del medi natural, social $\mathrm{i}$ cultural, de la llengua, d'educació física i d'educació artística visual i plàstica, com a més importants.

Creiem també que el joc és una activitat generadora de plaer que es realitza amb finalitats que li són implícites, en la qual els nens es diverteixen amb fantasia i llibertat i que més tard comparteixen amb els amics. D'altra banda, els jocs reglats contribueixen extraordinàriament a l'adquisició de pautes de comportament, ja que els nens han de respectar estrictament les regles, cosa que els proporciona possibilitats per exercitar en cada moment la capacitat d'autocontrol i d'autodomini bàsics.

A més, constitueix una forma de vida social que permet als jugadors situar-se en una esfera temporal $\mathrm{i}$ espacial diferent, afavorint l'assaig, la pràctica i l'aprenentatge de diferents actituds socials. D'altra banda, el joc en el paper d'afavoridor del desenvolupament físic i intel.lectual de les persones resulta essencial en la infància i conserva l'interès al llarg de tota la vida. Per tant, al marge de la utilització pedagògica o didàctica, es reconeixen les seves virtuts envers al creixement $i$ evolució dels infants en les diferents dimensions. $\mathrm{Hi}$ trobem units els tres àmbits bàsics per a una bona formació integral de la personalitat del nen: el cognitiu, el psicomotriu i el social i afectiu. A més, s'hi desenvolupen totes les funcions psíquiques (percepció, atenció, memòria, pensament, llenguatge i imaginació) i alhora actua com a accelerador dels aprenentatges. S'ha demostrat que el joc, lligat als comportaments d'exploració i de curiositat, constitueix el motor de l'aprenentatge i de la descoberta en l'infant.

De vegades a les facultats d'Educació planen les grans paraules i els grans principis, però el currículum necessita el gest petit. Hi ha coses petites i grans que no s'obliden mai, i això és el que representa per a molts alumnes de Magisteri compartir amb els escolars una primera experiència real. Quan el pas del temps doni relleu al record, quedarà l'experiència.



